\title{
Cinquenta anos de literatura angolana
}

\author{
Ana Paula Tavares*
}

* Escritora e crítica angolana. 
A Critica e a História literárias falam habitualmente de um longo silêncio para caracterizar o período da literatura angolana e de Angola que se segue ao fim da "Imprensa Livre" e a um longo tempo caracterizado pela actividade febril dos "filhos do país" e dos seus múltiplos resultados patentes nos diferentes periódicos que, depois de 1860, apareceram nas principais cidades angolanas.

Entre as duas guerras Angola, tal como as outras colônias portuguesas, vive, aparentemente em silêncio e assiste às transformações decorrentes da verdadeira implantação do regime colonial. As fronteiras de dentro e de fora do país cumprem-se diante da maior ou menor resistência dos africanos, enquanto a greIha administrativa, económica e social se aperta.

Entretanto e no que à poesia diz respeito, é de um silêncio povoado de vozes, de.estatura e estrutura muito diferentes, aquele que se pode escutar no caso de Angola. Um poeta como Tomás Vieira da $\mathrm{Cruz}^{1}$ construiu, nesse período, uma vasta obra, reunida em livro e publicada em três volumes, onde sacrifica aos trópicos a sua voz portuguesa, com um olhar de fora, mas não distanciado, recuperando um universo musical, que deu cor e sentido ao seu tropismo por Angola². Rompem ainda o silêncio as vozes originais de Lília da Fonseca e G eraldo B essa Victor, dois produtores com obra feita em Angola que mais tarde a deixaram física e literariamente.

Castro Soromenho, seguindo percursos de grande diversidade, resgata para a literatura a vida dos sertões de Angola, pelos caminhos dos Homens sem Cami -

\footnotetext{
Tomás Vieira da Cruz - nascido no R ibatejo, Portugal, vive em Angola desde 1922. M orre em 1960.

V. p. ex. Cazumbi, Poesia de Angola, editada em 1950.
} 
nho. "E screvendo em português, ele climatiza, ideologiza e universaliza o choque que gerou a "Angolanidade", diz Costa Andrade $\mathrm{A}^{3}$, o poeta angolano a quem se deve nos anos sessenta a definição dos contornos e do conteúdo desse conceito operativo a partir dessa data.

Mário Antônio Fernandes de Oliveira, poeta e ensaíta angolano de grandes recursos, aponta, em muitos dos seus trabalhos, a importância das colaborações no jornal A Província de Angola, e dos círculos de interesse e tertúlias formadas em tomo do Liceu Salvador Correia, fundado em 1919 e durante algum tempo única instituição de ensino liceal existente em Angola, estabelecendo pontes interessantes com alguma poesia portuguesa e possibilitando aos alunos o conhecimento de nomes como J osé B lanc de Portugal, J orge de Sena e R uy Cinatti. ${ }^{4}$

Dos quadros do Liceu, Mário Antônio ressalta a actuação de Alves da Cunha, ligado à fundação do M useu de Angola e reorganização da documentação de carácter histórico e de Cruz Malpique, directamente relacionado com a fundação em 1942 da Sociedade Cultural de Angola. O jornal desta Sociedade, Cultura, com duas séries, será na sua segunda fase (1957-1961-13 nos) o veículo por excelência das vozes que tecem o modernismo da literatura, sobretudo da poesia e do ensaio, de Angola.

Pode dizer-se que entre a primeira fase e a segunda de Cultura um movimento pendular se institui e o que sobra é realmente para a segunda fase um resgate dos temas angolanos e de Angola como objecto principal da revista.

[...] e nós vamos remontar [...] ao ano de 1948. Que é o ano de referência para a tal geração chamada dos "Novos Intelectuais de Angola " ou do "Vamos descobrir Angola" ou da “M ensagem". Uns situam em 48, outros em 50. Nós vamos situar em 48.

Assim e numa palestra nunca publicada, proferida no P.U.N.I.V.-, em L uanda, em Maio de 1989, Antônio J acinto5, poeta de "Carta de um Contratado" e contemporâneo destes movimentos, contava como tudo tinha acontecido.

E sta palestra, juntamente com todas as marcas da oralidade, conserva a presença tímida do poeta do $\mathrm{K}_{\text {iaposse }}{ }^{6}$, e caracteriza esse movimento que se propunha franquear a muralha de silêncio construida pelo colonialismo e que separava os intelectuais filhos de colonos e de assimilados do povo angolano.

Angola entra na década de quarenta com o sistema colonial e os seus modelos e padrões, practicamente estabelecidos. Economicamente as produções do

\footnotetext{
Citado por Salvato Trigo, A Poética da Geração Mensagem, Porto, Brasília E ditora, 1979.

V. : “Os Poemas do Itinerário Angolano" publicados nos Cadernos Capricórniono 18, Lobito, 1974.

Antônio J acinto do Amaral. Martins, nascido em Luanda (embora preferisse ter nascido no Golungo Alto) em 1922 e falecido em Lisboa, em 1992, deixou vasta obra dispersa em muitas Antologias; autor de contos.

Pequeno rio da localidade angolana do Golungo- Alto
} 
café e do algodão tinham obrigado a uma reordenação dos espaços. A quadrícula da ocupação reduzira consideravelmente a iniciativa e capacidade de resposta dos africanos. O interior do país fechava-se. Às cidades, no entanto, embora de forma ténue, os ecos dos movimentos mundiais (pan-africanismo, negritude) iam chegando. Nas colónias de lingua inglesa criavam-se as primeiras universidades.

Nas principais cidades da colónia, instituições de carácter mais ou menos associativo, operativas desde o princípio dos anos quarenta e que possuem os seus próprios orgãos de imprensa, reservam margens de liberdade para dar espaço à "questão angolana" que entretanto se ia de uma maneira ou de outra formulando.

[...] assim se formou um grupo ocasional em casa de um amigo, em casa de Humberto M achado... Um sobrinho que ele tinha, Higino Aires, que se fazia rodear de um certo grupo de jovens e é o mesmo Higino Aires que batizou esse grupo que se reunia uma vez por semana à noite, de "E lenco". [ ...] Também se falava de poesia [ ...]

Esse grupo chamava-se "Elenco" e não é "Vamos descobrir Angola” mas aí começa [...]

Assumindo uma voz de griot, Antônio J acinto resume assim como tudo começou e é testemunho de alguém que fez parte do "elenco" que havia de "D escobrir Angola" e navegar "M ensagem" e "Cultura", pagar isso tudo no campo de concentração do Tarrafal, ser guerrilheiro, ministro, deputado e retirar-se com passos pequenos da política e da vida, quando o projecto de nação que ajudou a descobrir se revelou longe da vertente cultural que sempre lhe atribuiu.

Entre quarenta e cinquenta, os quintais de L uanda acendiam-se ao ritmo do N'Gola Ritmos e a palavra prolongava-se em torno da discussão de temas angolanos, em busca de um movimento de renovação que colheria os seus primeiros frutos no "Movimento dos Novos I ntelectuais de Angola".

Conciliar um imaginário poético com uma práxis é caminho que começa apresentar-se profícuo para uma geração que, se ainda não tem respostas, assumiu, por inteiro, o direito de se interrogar.

Antônio J acinto situa em 1948 a palestra que o caboverdeano Filinto Elísio de Menezes, poeta da geração "Certeza"7 proferira na Sociedade Cultural de Angola ${ }^{8}$ para denunciar a inexistência de uma "verdadeira crítica literária" que peneirasse a literatura louvaminheira e de ocasião da que começando a despontar iria verdadeiramente rasgar os caminhos para uma literatura merecedora do qualificativo angolana.

7 Movimento cultural e literário levado a cabo pelos alunos do Liceu Gil Eanes em Cabo Verde e que se pretendeu sucessor de "Claridade".

$8 \quad$ Separata da Revista Cultura, Luanda, 1949 
Serve de esteio a esta tomada de posição iconoclasta o modelo brasileiro, mesmo se, como alguns estudiosos o afirmam, mal conhecido ${ }^{9}$, tendo Maurício de Almeida Gomes ${ }^{10}$ glosado no poema "Exortação" os poetas brasileiros Ribeiro Couto e Manuel Bandeira, gritando ser preciso "criar a nova poesia de Angola". Essa nova poesia/forte, tema, nova e bela/ amálgama de lágrimas e de sangue/ sublimação de muito sofrimento/afirmação de uma certeza". ${ }^{11}$

Pela primeira vez se evoca o passado como exemplo para reforçar as novas razões de Angola. O movimento "A Voz de Angola Clamando no Deserto" é reclamada como uma tradição e citada para representar como poderia ser forte a voz dos naturais de Angola ou filhos do país como se designavam a si próprios.

[...] Tomás- Bem! A poesia, jovem, não se explica. É um fogo que nos abrasa, um ar que nos dá. Mas enfim... Conhece o Assis?

Paulo - Qual Assis? O das musicadas?

Tomás - Quais inusicadas! O diccionário do Assis. Não? Incrível! Pois, jovem conselho numar um: compre o Assis.

Numar dois: Leia e medite esse diccionário. E talvez Ihe pareça profético mas a verdade é esta : sem o Assis não haverá poesia angolana!

Desta forma, recheada de fina ironia, Luandino Vieira, a voz absoluta do romance angolano reconstitui, na sua "Estória de Família"12 o nascimento da moderna literatura angolana e de como ela criou os seus clássicos, colocando no panteão de referência Antônio de Assis Júnior, o autor do Diccionário K i mbundu Português e do Romance de Costumes Angolenses, que ao revelar os segredos da morta, tão bem caracteriza essa sociedade complexa e dividida entre mundos diferentes no triângulo Luanda - Dondo-L uanda com a cumplicidade de Kuanza. ${ }^{13}$

A geração dos mais novos necessita do tom ancestral dos tambores que marque um ritmo diferente à língua portuguesa e dela se aproprie.

Os ecos desta empresa de descoberta chegam a Lisboa e são contados e ao no 37 da R ua Actor Vale, onde se reuniam habitualmente Agostinho N eto, A mílcar Cabral, Vasco Cabral e Mário de Andrade para só referir alguns dos frequentadores. É Viriato da Cruz que faz chegar, por carta, as novas e as intenções de Luanda.

\footnotetext{
Cf. Mário Antônio Fernandes de Oliveira, Reler Áftica, p.184

Maurício Ferreira Rodrigues de Almeida Gomes, nascido em L uanda em 1920

Cf- No Reino de Caliban, 11, p. 88

Luandino Vieira,"Estória de família" in. Lourentinho, Dona Antônia de Sousa Neto \& Eu, Lisboa, E dições 70, 1981, p. 109

13 Cf. Antônio de Assis J únior, O Segredo da Morta,Romance de Costumes Angolenses, Luanda, U.E.A-1985.
} 


\section{A profecia antes da mensagem}

Figura tutelar, deste e dos movimentos seguintes, Viriato da Cruz vai marcar com a sua obra os intelectuais de Angola, abrindo os caminhos possíveis para os rumos da literatura angolana, de forma tão forte que a música, a dança, o quotidiano em mudança habitam os seus poemas numa apropriação do real que confere eficácia ao caminho da literatura angolana. J untamente com Agostinho Neto e Antônio J acinto seguram as pontas de um movimento que arrastaria muitos nomes ainda hoje com lugar marcado na literatura que se faz em Angola.

Linguagem demanifesto, documento defundação, constituem as marcas deágua a separar a apropriação de um tempo feita por um grupo de jovens para os quais literatura étambém apropriação de um território da verdade para o qual apelam os lexemas povoados de uma carga semântica positiva como : terra, canto, verdadeira.

É a fala de uma geração "mais consciente de si propria e da diferença que tem que assumir para o futuro". O momento de que se fala é um momento onde se forjou e se inscreveu uma actividade literária e cultural com fortes implicações ideológicas: trata-se dos primeiros sinais de reconhecimento de uma identidade que se queria nacional e libertadora.

A poesia constitui-se como a voz particular que organiza e dá sentido a um quotidiano perturbado e o poeta mesmo quando diz “Não é este este ainda o meu poema/ o poema da minha alma e do meu sangue não/ Eu ainda não sei e não posso escrever o meu poema/"14, assume o estatuto de uma fala outra perdida nos misseke, recuperada no grande movimento de descoberta da terra.

Entre tradição e ruptura se faz a afirmação deste momento novo, com as saudades da infância, lugar ameno, perdido para sempre, cidade e infância descendo as avenidas de alcatrão, particular travessia do inferno cortada com o choro dos contratados.

Na palestra a que já fiz referência ${ }^{15}$, Antônio J acinto cita Mário Antônio para concordar que na origem de muitos destes grupos e movimentos estaria muita boémia intelectual:

[...] O movimento nunca publicou um livro, nunca publicou uma revista, mas tudo foi saindo nas Mensagens, antologias, cadernos antológicos... Por isso nós podemos chamar o movimento como uma corrente, incluindo até pessoas que não se conheciam.[... ]

Com existência formal, de manifesto e tudo a partir de 1948, ou nascido muito antes nas páginas do jornal O Farolim ( 1946 - a partir de um texto de Agostinho

\footnotetext{
António J acinto- "Poema da Alienação", in No Reino de Caliban II, p. 136

Agradeço a Ruth Lara e a Conceição Neto a amabilidade de ma terem confiado.
} 
Neto "Marcha para o Exterior"), ou nunca enunciado enquanto tal, o movimento "Vamos descobrir Angola" ganha identificação na obra posterior dos autores, sobretudo poetas, angolanos, que crescem literariamente, nos anos cinquenta e sessenta, publicados em Cultura, Mensagem, antologiados pela Casa dos E studantes do Império, citados por quem redescobre o passado Angolano muito para além da sua existência de e no papel. 
